\title{
Clinical Features, Management and Outcome of Snake Bite in Children in Manipal Teaching Hospital
}

\author{
Koirala DP, ${ }^{1^{*}}$ Gauchan E, ${ }^{1}$ Basnet $S,{ }^{1}$ Adhikari $S,{ }^{1} B K G^{1}$ \\ ${ }^{1}$ Department of Pediatrics, Manipal College of Medical Sciences, Pokhara, Nepal
}

*Corresponding Author:

Dr. Deepak P Koirala,

Lecturer, Department of Pediatrics

MCOMS, Pokhara, Nepal

E-mail: dpkoirala19@hotmail.com

\section{Citation}

Koirala DP, Gauchan E, Basnet S, Adhikari S, BK G. Clinical Features, Management and Outcome of Snake Bite in Children in Manipal Teaching Hospital. Nepal Journal of Medical sciences 2013;2(2):119-24.

\begin{abstract}
Background: Snake bite is a widely distributed and neglected condition with a significant mortality. Medically significant snakes are: Elapidae, which are mainly neurotoxic and Viperidae, which are hemotoxic. Most studies on snake bites are done in Terai belt of Nepal and this is a first study of its kind in children in western region of Nepal.
\end{abstract}

Methods: This was a 7 year retrospective study in Pediatric unit of Manipal Teaching Hospital, Pokhara, Nepal. Relevant data from all cases of snake bite in children up to 18 years of age was collected in a structured proforma and analyzed.

Results: Among the 39 cases of Snake bites; it was more in boys $(\mathrm{M}: \mathrm{F}=1.16: 1)$, from rural areas $(62 \%)$ and was more common during monsoon (64\%). The commonest site of bite was foot $(64 \%)$. Snakes were identifiable in only $23 \%$ of the cases. Local swelling (77\%) and pain (74\%) were common clinical features. Coagulation profile was deranged in $80 \%$ of the patients, hematuria was observed in $13 \%$ patients and $15 \%$ patients had thrombocytopenia. Most of the snakes were hemotoxic $(77 \%)$ and only 1 case $(2.5 \%)$ was neurotoxic. Only $44 \%$ of the patients received polyvalent anti-snake venom and blood products were required in $51 \%$ of the patients. Most patients improved (75\%) and the case fatality rate was $2.5 \%$.

Conclusion: Most snakes found in mountainous region of Nepal are hemotoxic and lead to deranged coagulation profile. Mortality is low in hemotoxic as compared to neurotoxic envenomations.

Keywords: Anti-snake venom; hemotoxic; neurotoxic; snake-bite

\section{Background:}

Out of 3000 species of snakes found worldwide, about $15 \%$ are considered dangerous to human life. ${ }^{1}$ A widely distributed and neglected condition, the incidence is quite high in rural warm regions of Terai $^{2}$ and even in the mountainous regions of Nepal. Although the exact incidence is unknown, about $20 \%$ of the bites result in no envenomation and $10 \%$ result in mortality. ${ }^{3}$
According to World Health Organization, more than 20,000 cases of snake bites and 1,000 deaths may occur annually. A community based study in South-eastern Nepal showed an annual incidence of 1162 bites/100000, annual mortality rate of $162 / 100000$ and case fatality rate of $27 \% .^{2}$ Most snake bites are accidental as snakes usually do not bite without provocation. Most of the medically significant snakes in the world can be divided into two groups- Elapidae, which 
are usually neurotoxic and Viperidae, which are usually are usually hemotoxic. ${ }^{3,4}$ Few studies have shown that elapids (Cobras and Kraits) are the important cause of envenomations in the Terai belt of Nepal. ${ }^{5-7}$ This study is conducted to evaluate the clinical features, management and outcome of these snake bite envenomations in children. This is a first study of its kind done in children in this region of Nepal.

\section{Methods:}

This was a 7 year retrospective study done in a Pediatric Intensive Care Unit (PICU) of Manipal Teaching Hospital (MTH), Pokhara, Nepal. MTH is a tertiary referral centre and gets its referrals from Regional hospital, Medical Colleges and other Zonal and District Hospitals of the Western Development Region of Nepal.

All cases of Snake bite in children up to 18 years of age admitted in the PICU from 2006 January to 2012 December were included in the study. Data regarding demographic features, presentation and features of envenomation, treatment details, complications and outcome were collected in a structured proforma. Data were then analyzed using Microsoft excel. Only those cases where there was definitive evidence of snake bite were included in the study. Dubious cases were omitted from the study.

\section{Results:}

There were 39 cases of Snake bite, which constituted 20.8\% of the total poisoning cases (187) over a period of 7 years. The male to female ratio was $1.16: 1$ and more cases were from rural areas $(62 \%)$ than urban areas. Most of the patients admitted were more than 5 yrs $(85 \%)$ as shown in Table 1 .

Table 1: - Demographic distribution of Subjects

\begin{tabular}{lcc}
\hline & Parameters & Number (\%) \\
\hline Total subjects (39) & Male & $21(54 \%)$ \\
& Female & $18(46 \%)$ \\
Locality & Rural & $24(62 \%)$ \\
& Urban & $15(38 \%)$ \\
Age (yrs) & $0-5$ & $6(15 \%)$ \\
& $5-10$ & $17(44 \%)$ \\
& $\geq 10$ & $16(41 \%)$ \\
\hline
\end{tabular}

In all the years of study, there were cases of snake bite and year 2011 had maximum number of admissions as shown in Fig 1. Over a 7 year study period, snake bite cases were maximum during the monsoon season i.e. June, July and August (64\%).

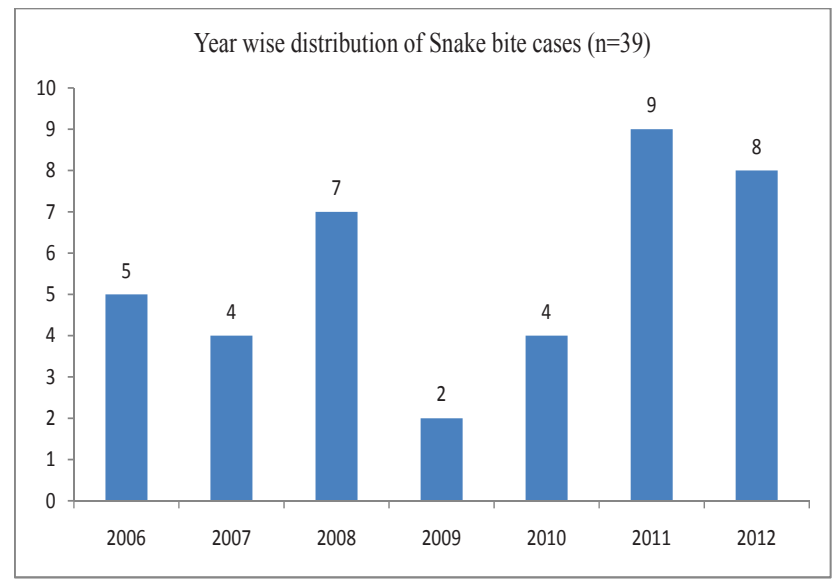

In the month of December, January, February and April no case of snake bites were admitted (Fig 2).

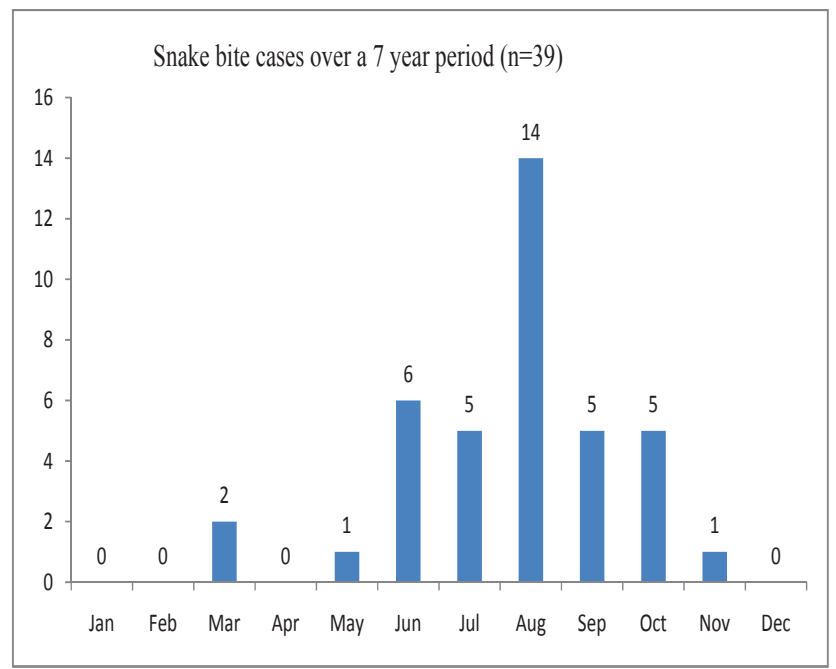

Maximum cases of snake bite $(46 \%)$ were from Kaski district and least cases were admitted from Myagdi district (5\%). Baglung, Parbat, Tanahun and Syanja districts also had cases of snake bite as shown in Fig 3.

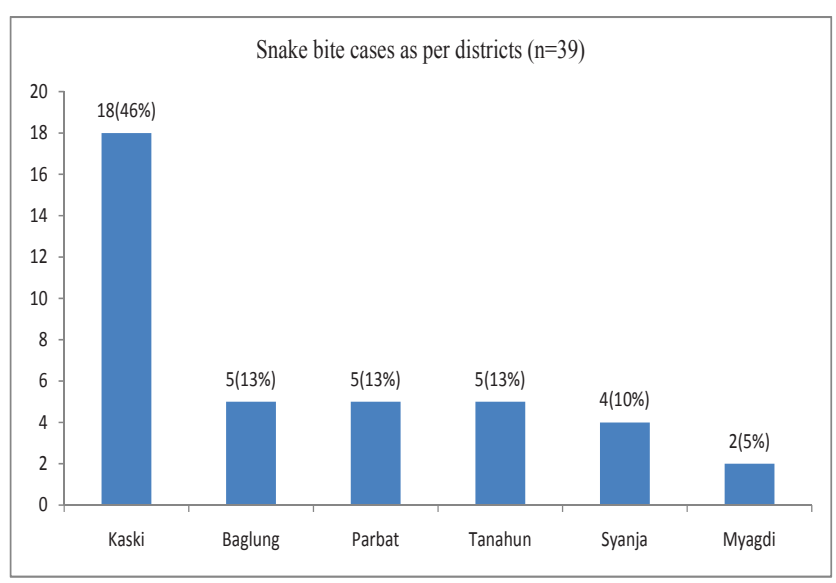


Foot was the most common site of bite (64\%) and face was the least common (8\%) site of bite (Fig 4).

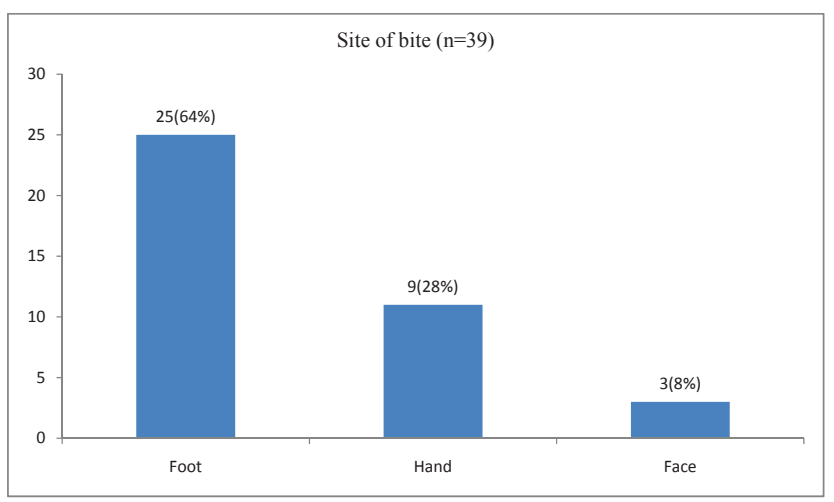

The grades of envenomation seen in our study patients were Grade 0 (21\%), Grade 1 (28\%), Grade 2 (36\%) and Grade 3 $(15 \%)$ as shown in Fig 5.

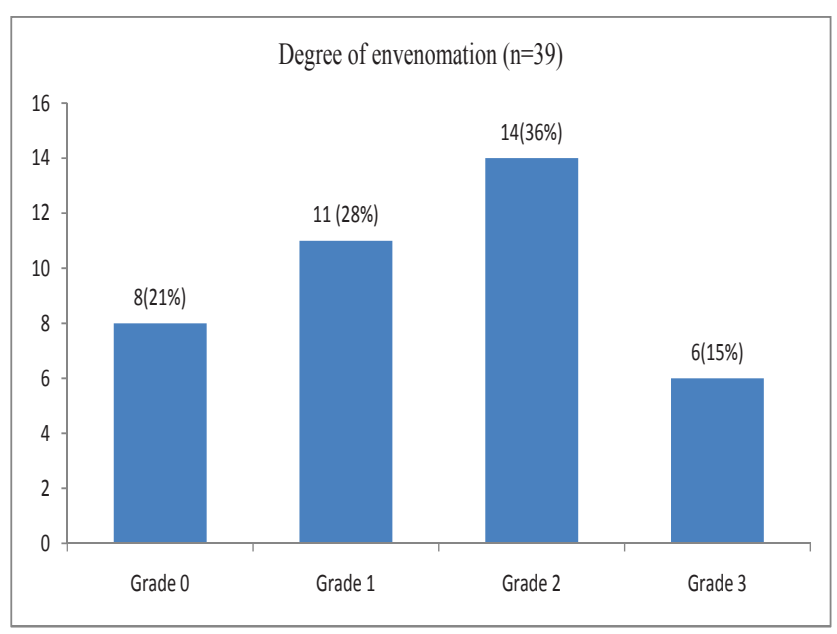

Nine out of 39 of the cases $(23 \%)$ were identified as green pit-viper and rest were unidentified (Fig 6).

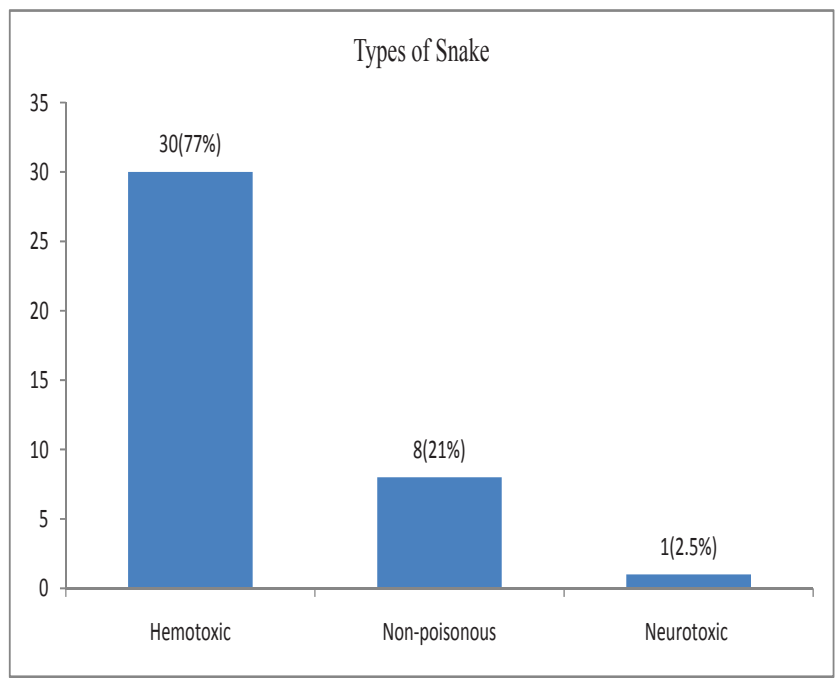

Table 2 shows clinical features. Local swelling (77\%) and pain $(74 \%)$ were the common clinical features. Bleeding from bite site, local tissue necrosis, ecchymotic edema and hemorrhagic blisters were also observed.

Table 2:- Clinical Features $(n=39)$

\begin{tabular}{|c|c|c|}
\hline \multicolumn{2}{|c|}{ Features } & \multirow{2}{*}{$\begin{array}{l}\text { Number (\%) } \\
30(77 \%)\end{array}$} \\
\hline 1) & Local swelling & \\
\hline 2) & Local pain & $29(74 \%)$ \\
\hline 3) & Bleeding from bite site & $27(69 \%)$ \\
\hline 4) & Local tissue necrosis & $10(26 \%)$ \\
\hline 5) & Ecchymotic edema & $6(15 \%)$ \\
\hline 6) & Hemorrhagic bleb/blister & $5(13 \%)$ \\
\hline
\end{tabular}

All these features were suggestive of hemotoxic envenomation. In one case there was swelling of hand associated with burning sensation; ptosis, headache, respiratory muscle paralysis and coma were also observed. These features were suggestive of neurotoxic envenomation. Table 3 shows laboratory investigations. INR was prolonged in $80 \%$ of the cases and $20 \%$ of the patients had normal INR. Hematuria was observed in $13 \%$ of the patients.

Table 3:- Laboratory investigations

\begin{tabular}{lll}
\hline \multicolumn{2}{l}{ Parameters } & \\
\hline INR & Range & Number (\%) \\
& $1-1.5$ & $8(20 \%)$ \\
& $1.5-3.0$ & $6(15 \%)$ \\
& $3.0-5.5$ & $3(8 \%)$ \\
& Didn't clot in 2 mins & $22(56 \%)$ \\
Urine & Hematuria & $5(13 \%) \quad 2$ (Microscopic) \\
& & $34(87 \%)$ \\
& Normal (Gross) \\
CBC & Thrombocytopenia & $6(15 \%)$ \\
& Normal & $33(85 \%)$ \\
\hline
\end{tabular}

CBC was normal in $85 \%$ of the patients and $15 \%$ of the patients had thrombocytopenia. Renal function test (RFT) was normal in all the patients. After analysis of the laboratory reports and clinical features, maximum types of snakes we have seen in our study were categorized as hemotoxic (77\%). Only $1(2.5 \%)$ case was neurotoxic and rest were non-poisonous (21\%) (Fig 7).

Table 4 shows treatment parameters. Among the treated cases, $69 \%$ of the cases were referred and $31 \%$ came directly to MTH for treatment. 
Table 4:- Treatment parameters

\begin{tabular}{|c|c|c|}
\hline \multicolumn{3}{|l|}{ Parameters } \\
\hline \multirow[t]{2}{*}{ Type of cases } & Referred & $27(69 \%)$ \\
\hline & Came directly to MTH & $12(31 \%)$ \\
\hline $\begin{array}{l}\text { Time since bite on admission } \\
\text { (hrs) (Mean } \pm \mathrm{SD} \text { ) }\end{array}$ & $8.97 \pm 8.53(0.5-24 \mathrm{hr})$ & \\
\hline \multirow[t]{2}{*}{ Treatment place } & PICU & $7(18 \%)$ \\
\hline & Emergency & $32(82 \%)$ \\
\hline \multirow[t]{5}{*}{ ASV (Anti-snake venom) } & Given & $17(44 \%)$ \\
\hline & Not given & $22(56 \%)$ \\
\hline & Dose (vials) & $13.29 \pm 14.7$ \\
\hline & $($ Mean \pm SD $)$ & (Range $=3-65)$ \\
\hline & Allergic reaction & $3(18 \%)$ \\
\hline \multirow{4}{*}{$\begin{array}{l}\text { ASV use in various grades of } \\
\text { envenomation }(n=17)\end{array}$} & Grade 0 & $0(0 \%)$ \\
\hline & Grade 1 & $3(18 \%)$ \\
\hline & Grade 2 & $10(59 \%)$ \\
\hline & Grade 3 & $4(23 \%)$ \\
\hline \multirow{2}{*}{$\begin{array}{l}\text { Use of blood products in } \\
\text { course of treatment }(n=20)\end{array}$} & Whole blood & $6(30 \%)$ \\
\hline & FFP & $14(70 \%)$ \\
\hline $\begin{array}{l}\text { Duration of hospitalization } \\
\text { (days) (Mean } \pm \text { SD) }\end{array}$ & \multicolumn{2}{|l|}{$4.98 \pm 4.05$ (Range $=1-25)$} \\
\hline \multirow[t]{3}{*}{ Outcome } & $1(2.5 \%)$ & \\
\hline & LAMA $\quad 9(23 \%)$ & \\
\hline & Improved $29(74 \%)$ & \\
\hline
\end{tabular}

The mean time since bite on admission was $8.97 \mathrm{hrs}(\mathrm{SD}=$ $8.53 \mathrm{hrs}$, Range $=0.5-24 \mathrm{hrs}$ ). The initial treatment place was emergency department in $82 \%$ of the cases and PICU in $18 \%$ of the cases. Anti-snake venom (ASV) was given to 17 cases (44\%) and mean dose of ASV required was 13.29 vials $(\mathrm{SD}=14.7$, range $=3-65)$. Among the patients receiving $\mathrm{ASV}$, the maximum patients had grade 2 envenomation $(59 \%)$. Three patients $(18 \%)$ developed allergic reaction to ASV. There was use of blood products in 20 patients (51\%), among these 14 patients required fresh frozen plasma (FFP) and 6 patients required fresh whole blood. The mean duration of hospitalization was 4.98 days $(\mathrm{SD}=4.05$, range $=1-25)$. There was only 1 mortality $(2.5 \%)$, 9 patients (23\%) left against medical advice (LAMA) and 29 patients $(74 \%)$ improved and were discharged following treatment. No complications or sequel were seen in survived patients.

\section{Discussion:}

Over a 7 year study period, snake bites constituted $20.8 \%$ $(39 / 187)$ of total poisoning cases. The male to female ratio was 1.16:1. This result was similar to other studies done in children. ${ }^{6,7}$ More cases of snake bites were from rural areas than urban areas. Male children because of their inquisitiveness and activity tend to play outdoors that may be the reason they are more prone to snake bites. Snake being cold blooded animal lives in bushes and holes so they are more common in agricultural rural areas of western Nepal but it was not uncommon to find cases of snake bite in urban areas. This was mainly because of cases from Pokhara, where vegetations and agricultural farmlands are ample within city area. Most children were more than 5yrs which is age of maximum ambulation and children of more than $10 y$ rs work at fields in rural Nepal. This was similar to finding in another study. ${ }^{7}$

Most of the snake bite cases occurred during the monsoon season i.e. June, July and August which was similar to a finding in a study done in terai. ${ }^{6-9}$ Monsoon is a summer season and because of this snakes come out of their holes after hibernation. Also it's a cultivating season in Nepal and there is a lot of human activity in fields. This may be the reason behind increased incidence of bites during summer season. Kaski had maximum cases of snake bite (46\%). Patients were also referred from neighboring districts like Baglung, Parbat, Tanahun, Syanja and Myagdi. MTH being in Kaski district may be the reason that we were getting maximum cases from this district. Also, it is quite common to find agricultural farmlands within Pokhara and its surroundings despite urbanization. Foot was the most common site of bite (64\%) followed by hand (28\%) and face (8\%). Similar finding was shown in another study. ${ }^{6}$ In our study, as more victims were more than $5 \mathrm{yrs}$, they are active, ambulatory and tend to play outdoors. So, they have chances of stepping up on the snake and more chances of bite on foot.

Grade 0 (no envenomation) was seen in $21 \%$ of the patients whereas there were maximum patients of Grade 1 and 2 envenomation (64\%) and Grade 3 (severe) envenomation was seen in $15 \%$ of patients. However, no studies were found showing similar findings. Depending upon the clinical features and laboratory parameters various grades of envenomations are described as shown in table below.

\section{Grades of envenomation $^{3,10,11}$}

Grade 0 - no envenomation

Grade 1 - minimal envenomation (local swelling and pain without progression)

Grade 2 - moderate envenomation (swelling, pain or ecchymosis progressing beyond the site of injury, mild systemic or laboratory manifestations)

Grade 3 - severe envenomation (marked local response, severe systemic findings, and significant alteration in laboratory findings) 
Children have smaller body size and the venom injected per kg body weight is more as compared to adults, so envenomation is more severe in children as compared to adults. ${ }^{12}$ Most of the snakes $(77 \%)$ in our study were unidentified and $23 \%$ were identified as green pit-vipers. In one study $60 \%$ of the snakes were unidentified, 29\% were krait, 10\% were cobras and $1 \%$ were viper. ${ }^{6}$ In another study $52 \%$ were unidentified, $40 \%$ were krait and $8 \%$ were cobras. ${ }^{7}$ This was because children cannot identify the snakes properly and in our part of Nepal, as most of the snakes are non-poisonous and not a threat to human life even adults seldom identify the snakes.

The clinical features seen in our study were predominantly hemotoxic. No study giving emphasis on clinical features were found. Only one case presented with neurotoxic envenomation features. Snake venom contains many types of enzymes, non-enzymatic polypeptide toxins and nontoxic proteins. Some of them act as procoagulants causing defect in the coagulation cascade. Some damage tissues causing edema and necrosis whereas some neurotoxins bind to acetylcholine receptors at the motor end -plate leading to a variety of neurological signs and symptoms. ${ }^{3,4}$

The INR was deranged in $80 \%$ of the cases. In 22 cases $(56 \%)$, the coagulation profile was deranged severely with prothrombin time $(\mathrm{PT})>2$ minutes. In one study done in Perth (Australia), there was similar derangement of coagulation profile. ${ }^{13}$ Snake venom cause defect in hemostasis by activation of coagulation cascade and endogenous plasminogen system at various sites, and direct degradation of fibrinogen by fibrinogenases. ${ }^{3}$ In those cases who had hematuria, all of them had elevated INR. It can be due to defect in coagulation and direct cytolytic effect of venom on kidney tubules. ${ }^{3}$ Thrombocytopenia was found in $15 \%$ of the cases and renal function tests were normal in all the patients.

Most of the snakes were unidentified in our study and we had to rely mainly on clinical features and laboratory reports to classify the snakes. In our study most were hemotoxic (77\%), only 1 was neurotoxic (2.5\%) and $21 \%$ were classified as non-poisonous. All 9 cases (23\%) identified as green pit-viper were hemotoxic. Among those identified as non-poisonous, the possibility of dry bites by poisonous snakes could not be ruled out. Our finding was different from other studies done in Terai belt of Nepal where the snakes bites were predominantly neurotoxic. , $6-8^{-8}$

MTH is a tertiary referral centre and most of the cases (69\%) we have treated were referred to us. The mean time since bite on admission was $8.97 \mathrm{hrs}(\mathrm{SD}=8.53$, range $=0.5-24)$. Only those cases that came from far-off districts came late. Only $44 \%$ of the patients received ASV and most of them (82\%) had grade 2 or 3 envenomations. ASV was given to the patients depending upon the affordability, availability and severity of coagulation profile derangement. The mean dose of ASV used was 13.29 vials $(\mathrm{SD}=14.7$, range=3-65) and $3(18 \%)$ patients developed allergic reaction to ASV. The allergic reaction was treated with steroids and antihistamines and there was no fatality to it. Slightly higher mean dose of ASV was found in a study by Poudel KM et al. ${ }^{7}$ Fresh whole blood and fresh frozen plasma (FFP) were used in 51\% of the patients and all of them had deranged coagulation profile. Blood products were used depending upon its availability and derangement of coagulation profile. The mean duration of hospitalization was 4.98 days $(\mathrm{SD}=4.05$, range $=1-25)$.

In our study, $74 \%$ of the cases improved after treatment, $23 \%$ of cases left against medical advice (LAMA) and 1 case $(2.5 \%)$ expired in course of treatment. The case fatality rates in other studies were in the range of $15.9 \%-28 \% .{ }^{6,7}$ In these studies, the snakes were mainly neurotoxic and most of them had features of respiratory paralysis. In a study done in Dharan, the mortality was higher among patients with features of neurotoxicity. ${ }^{14}$ The high percentage of LAMA cases can be due to ignorance of the public to understand the seriousness of the condition and also to understand that it is a treatable condition. The mortality in our study was a 13 year old male child from Parbat who came to the hospital at 8 hours of bite on the hand. He received 5 vials of ASV and developed allergic reaction to the treatment. The reaction was treated with steroids and antihistamines. The child had features of neurotoxic envenomation and expired at 14 hours of admission due to respiratory failure and coma. No complications or sequel were seen in survived patients.

\section{Conclusion:}

Snake bite is common in Western region of Nepal. Envenomations are mainly hemotoxic and neurotoxic envenomations are rarely found. Proper and timely monitoring of coagulation profile and prompt utilization of ASV and blood products is important in the management of snake bite cases. Mortality is low in hemotoxic as compared to neurotoxic envenomations.

\section{Funding: None}

\section{Conflict of interest: None}

\section{References:}

1. Gold BS, Dart RC, Barish RA. Bites of Venomous Snakes. N Engl J Med 2002;347:347-56. 
2. Sharma SK, Chappuis F, Jha N, et al. Impact of Snake Bites and Fatal Outcomes in South Eastern Nepal. Am J Trop Med Hyg 2004;71:234-8.

3. Animal Poisoning. In: Singh UK, Layland FC, P Rajniti, Singh S. Poisoning in Children. $3^{\text {rd }}$ Edition. New Delhi: Jaypee Brothers; 2006: 91-105.

4. Schroeder BJ, Norris RL. Envenomations. In: Kliegman, Stanton, St. Geme, Schor, Behrman, ed. Nelson textbook of Pediatrics. 19 $9^{\text {th }}$ Edition. Philadelphia: Elsevier Saunders; 2011:2460-62.

5. Sharma SK, Khanal B, Pokhrel P, et al. Snakebitereappraisal of the situation in Eastern Nepal. Toxicon 2003;41:285-9.

6. Shrestha BM. Outcomes of Snakebite Envenomation in Children. J Nepal Paediatr Soc 2011;31:192-7.

7. PaudelKM, Sharma S. Study ofClinico-Epidemiological Profile and Outcome of Poisonous Snake Bites in Children. J Nepal Paediatr Soc 2012;32:47-52.

8. Hansdak SG, Lallar KS, Pokharel P, et al. A clinicoepidemiological study of snake bite in Nepal. Trop Doct
1998;28:223-6

9. Joshi DD. An Epidemiological Study of Snake Bite Cases in Children of Nepal. J Nepal Paediatr Soc 2010;30:135-40.

10. Steve Holve. Envenomations. In: Kliegman, Behrman, Jenson and Stanton. Nelson Textbook of Pediatrics. $18^{\text {th }}$ Edition. Philadelphia: Elsevier Saunders 2007:2932-35.

11. Cribari C. Management of Poisonous Snakebites. American College of Surgeons. Committee on Trauma. Subcommittee on publications.2004;1-4.

12. Weber RA, White RR. Crotalidae envenomation in children. Ann Plast Surg 1993;31:141-5.

13. Mead HJ, Jelinek GA. Suspected snakebite in children: a study of 156 patients over 10 years. Med J Aust 1996; $164: 467-70$.

14. Heap BJ, Cowan GO. The epidemiology of snake bite presenting to British Military Hospital Dharan during 1989. J R Army Med Corps 1991;137:123-5. 